\title{
Propriedades farmacológicas do extrato etanólico de Eremanthus erythropappus (DC.) McLeisch (Asteraceae)
}

\author{
Marcelo S. Silvério, ${ }^{*, 1}$ Orlando V. Sousa, ${ }^{1}$ Glauciemar Del-Vechio-Vieira, ${ }^{1}$ Mariza A. \\ Miranda, ${ }^{1}$ Filipe C. Matheus, ${ }^{1}$ Maria A. C. Kaplan ${ }^{2}$ \\ ${ }^{1}$ Departamento Farmacêutico, Faculdade de Farmácia e Bioquímica, Universidade Federal de Juiz de Fora, \\ Campus Universitário, Martelos, 36036-330 Juiz de Fora-MG, Brasil, \\ ${ }^{2}$ Núcleo de Pesquisas de Produtos Naturais, Universidade Federal do Rio de Janeiro, Ilha do Fundão, \\ 21941-590 Rio de Janeiro-RJ, Brasil
}

\begin{abstract}
RESUMO: O presente trabalho investigou as propriedades antinociceptiva, antiinflamatória e antiulcerogênica do extrato etanólico dos galhos de E. erythropappus. Foram realizados os testes de contorções abdominais induzidas por ácido acético; tempo da lambida da pata induzida por formalina; placa quente; edema de pata induzido por carragenina; lesões ulcerativas induzidas por indometacina e etanol. As doses de 50, 100 e $200 \mathrm{mg} / \mathrm{kg}$ inibiram as contorções em 43,07\%, $69,34 \%$ e $70,07 \%$, respectivamente. O tempo da lambida da pata foi reduzido em ambas as fases nas doses testadas, enquanto o tempo de latência da placa quente teve efeito significativo na dose de $200 \mathrm{mg} / \mathrm{kg}$. O edema de pata foi reduzido em $23,81 \%(100 \mathrm{mg} / \mathrm{kg})$ e $47,62 \%(200 \mathrm{mg} / \mathrm{kg})$. O índice ulcerativo das lesões induzidas por indometacina foi reduzido na dose de $100 \mathrm{mg} / \mathrm{kg}$ e 200 $\mathrm{mg} / \mathrm{kg}$, enquanto a dose de $200 \mathrm{mg} / \mathrm{kg}$ teve efeito significativo sobre o volume e o $\mathrm{pH}$ do suco gástrico. O índice ulcerativo e o volume do suco gástrico, induzidos por etanol, foram reduzidos na dose de $200 \mathrm{mg} / \mathrm{kg}$, enquanto o pH do suco gástrico aumentou nas doses de 100 e $200 \mathrm{mg} / \mathrm{kg}$. Os resultados indicam que o extrato etanólico de E. erythropappus avaliado pode constituir alvo potencial para uso em terapias da dor, da inflamação e de úlcera.
\end{abstract}

Unitermos: Eremanthus erythropappus, atividade antinociceptiva, atividade antiinflamatória, atividade antiulcerogênica.

\begin{abstract}
Pharmacological properties of the ethanol extract from Eremanthus erythropappus (DC.) McLeisch (Asteraceae)”. The present work investigated the antinociceptive, anti-inflammatory and antiulcerogenic activities of Eremanthus erythropappus ethanol extract. The tests were carried out by acetic acid writhing, paw licking induced by formalin, hot plate, indomethacin- and ethanol-induced ulcer. The doses of 50, 100 and $200 \mathrm{mg} / \mathrm{kg}$ inhibited the contortions in $43.07,69.34$ and $70.07 \%$, respectively. Both phases of paw lick were reduced at the tested doses, while reaction time at hot plate had significant effect at $200 \mathrm{mg} / \mathrm{kg}$. The paw edema was decreased in $23.81 \%(100 \mathrm{mg} / \mathrm{kg})$ and $47.62 \%(200 \mathrm{mg} / \mathrm{kg})$. The index of ulceration induced by indomethacin was reduced at the doses of 100 and $200 \mathrm{mg} / \mathrm{kg}$, while $200 \mathrm{mg} / \mathrm{kg}$ decreased the gastric volume and $\mathrm{pH}$. The index of ulceration and gastric volume induced by ethanol was reduced at $200 \mathrm{mg} / \mathrm{kg}$, while the $\mathrm{pH}$ increased at 100 and $200 \mathrm{mg} / \mathrm{kg}$. The results indicate that the ethanol extract from E. erythropappus may constitute a potential target for the use in therapies of the pain, inflammation and ulcer.
\end{abstract}

Keywords: Eremanthus erythropappus, antinociceptive activity, anti-inflammatory activity, antiulcerogenic activity.

\section{INTRODUÇÃO}

Eremanthus erythropappus (DC.) McLeisch, sinonimizada de Vanillosmopsis erythropappa Schultz -Bip, pertence à família Asteraceae, é popularmente conhecida como "candeia-da-serra". No Brasil é encontrada nas regiões Nordeste, Centro-Oeste, Sudeste e Sul. Em Minas Gerais, a espécie predomina no alto das Serras da Mantiqueira e do Espinhaço (Pedralli et al., 1997). Essa espécie é usada na medicina popular como cicatrizante, no combate a infecções e no tratamento de úlceras estomacais (Silvério, 2004). O óleo essencial apresenta propriedades antibacterianas, antimicóticas, antiflogísticas, dermatológicas e espasmódicas (Silvério, 2004; Sousa et al., 2003).

Estudos químicos realizados em $E$. erythropappus identificaram $\alpha$-bisabolol, costunolídeo, eremantina, ciclocostunolídeo, vanilosmina, 15desoxigoyazensolídeo e substâncias derivadas do ciclocostunolídeo e da eremantina (Corbrella et al., 1974; Vichnewski et al., 1976; Lima et al., 1985). Outros sesquiterpenóides e lactonas sesquiterpenoídicas estão presentes no óleo essencial da madeira (Vichnewski et al., 1989; Braun et al., 2003). 
Devido as suas aplicações terapêuticas na medicina popular, o presente trabalho teve como objetivo investigar as propriedades antinociceptiva, antiinflamatória e antiulcerogênica do extrato etanólico dos galhos de E. erythropappus através dos modelos de nocicepção, inflamação e úlcera induzidos em animais de laboratório.

\section{MATERIAL E MÉTODOS}

\section{Coleta do material vegetal}

Eremanthus erythropappus foi coletada em Juiz de Fora, Minas Gerais, Brasil, em julho de 2005. Uma exsicata (CESJ n ${ }^{\circ}$ 25.363), identificada pela Dra. Fátima Regina Gonçalves Salimena do Departamento de Botânica da Universidade Federal de Juiz de Fora, foi depositada no Herbário Leopoldo Krieger desta universidade, Juiz de Fora, Minas Gerais, Brasil.

\section{Preparo dos extratos}

Os galhos foram submetidos à secagem a $50{ }^{\circ} \mathrm{C}$, sob ventilação, até perda de 90 a $95 \%$ de sua umidade. O material botânico (400 g) foi triturado em moedor elétrico BMC-0022 e pulverizado em tamis de malha 80. O extrato etanólico foi obtido por maceração estática durante um período de duas semanas com seis trocas de solvente. Após remoção do etanol por rotaevaporação, o extrato bruto foi solubilizado em dimetilsulfóxido (DMSO) 1\% (v/v) em salina para avaliação das atividades farmacológicas.

\section{Animais}

Foram utilizados camundongos Swiss (2530 g) machos e ratos Wistar (200-240 g) machos provenientes do Centro de Biologia da Reprodução da UFJF. Os animais foram mantidos em gaiolas plásticas com ração e água ad libitum em temperatura ambiente. Nas experiências das atividades antinociceptiva e antiinflamatória, os animais foram privados de ração 12 horas antes da realização dos procedimentos, enquanto na avaliação da atividade antiulcerogênica o tempo de jejum foi de 24 horas. Os protocolos utilizados foram aprovados pelo Comitê de Ética na Experimentação Animal (CEEA) desta instituição.

\section{Avaliação da toxidez aguda}

Grupos de 10 camundongos receberam doses de $0,5,1,1,5,2$ e $3 \mathrm{~g} / \mathrm{kg}$ do extrato etanólico de E. erythropappus por via oral, enquanto no grupo controle foi administrado salina. Os grupos foram observados por 48 horas, registrando-se a mortalidade dos animais (Dietrich, 1983). $\mathrm{A} \mathrm{DL}_{50}$ foi determinada através do método dos probitos usando a porcentagem da mortalidade e o logaritmo das doses (Litchfield \& Wilcoxon, 1949).

\section{Avaliação da atividade antinociceptiva}

\section{Teste de contorções abdominais}

O extrato etanólico (50, 100 e $200 \mathrm{mg} / \mathrm{kg})$ foi administrado em camundongos, por via oral (v.o.), uma hora antes da aplicação do ácido acético 0,6\% (n = 8) (Koster et al., 1959). Uma hora após tratamento, $10 \mathrm{~mL} / \mathrm{kg}$ de ácido acético $0,6 \%$ foram administrados intraperitonealmente e $\mathrm{o} \mathrm{n}^{\mathrm{o}}$ de contorções abdominais contado entre 10 e 30 minutos após esse procedimento. $\mathrm{O}$ grupo controle recebeu $10 \mathrm{~mL} / \mathrm{kg}$ de salina (v.o.) acrescida de DMSO $1 \%(\mathrm{v} / \mathrm{v})$. Indometacina $(10 \mathrm{mg} / \mathrm{kg}$, v.o.) foi o controle positivo do teste.

\section{Teste da formalina}

Injeção de $20 \mu \mathrm{L}$ de formalina $2,5 \%$ (em salina estéril) foi aplicada no espaço subplantar da pata direita de camundongos $(n=8)$ e a duração da lambida foi determinada de 0 a 5 minutos (primeira fase) e 15 a 30 minutos (segunda fase) após aplicação da formalina (Hunskaar \& Hole, 1987). O extrato de E. erythropappus foi administrado nas doses de 50, 100 e $200 \mathrm{mg} / \mathrm{kg}$ (v.o.) uma hora antes da injeção da formalina. Os animais controle receberam $10 \mathrm{~mL} / \mathrm{kg}$ de salina (v.o.) acrescida de DMSO 1\% (v/v). Morfina (1 mg/kg, subcutânea) foi usada como controle positivo do teste.

\section{Teste da placa quente}

Três grupos de oito camundongos foram tratados com o extrato etanólico $(50,100$ ou $200 \mathrm{mg} / \mathrm{kg}$, v.o.; $0,1 \mathrm{~mL} / 10 \mathrm{~g})$ e o grupo controle recebeu salina (10 $\mathrm{mL} / \mathrm{kg}$ ). Os animais foram colocados em placa quente aquecida a $55 \pm 1{ }^{\circ} \mathrm{C}$ (Franzotti et al., 2000). As medidas foram realizadas nos tempos $0,30,60$ e 90 minutos após administração do extrato, com tempo máximo de permanência (cut-off) de 40 segundos. Em um grupo de animais, o efeito do pré-tratamento com naloxona $(1 \mathrm{mg} / \mathrm{kg}$, s.c.) sobre a analgesia produzido pelo extrato (200 mg/kg, v.o.) foi determinado. Morfina ( $5 \mathrm{mg} / \mathrm{kg}$, s.c.), na ausência e na presença de naloxona, foi usada como controle positivo do teste.

\section{Avaliação da atividade antiinflamatória}

\section{Teste do edema de pata induzido por carragenina}

O edema de pata foi induzido pela injeção de $0,1 \mathrm{~mL}$ de carragenina $(2 \% \mathrm{p} / \mathrm{v})$ em salina estéril e administrada na região subplantar da pata direita de rato Wistar machos $(\mathrm{n}=6)$. Uma hora antes da injeção de carragenina, os extratos E. erythropappus foram 
administrados (v.o.) nas doses de 50, 100 e $200 \mathrm{mg} / \mathrm{kg}$ (Winter et al., 1962). O grupo controle recebeu $10 \mathrm{~mL} / \mathrm{kg}$ de salina (v.o.) com DMSO 1\% (v/v). Na pata esquerda, usada como controle, foi injetada $0,1 \mathrm{~mL}$ de salina estéril. Após quatro horas de injeção de carragenina, a medida do edema foi feita pela diferença entre o volume deslocado da pata direita e o da pata esquerda usando pletismômetro. Indometacina (10 mg/ $\mathrm{kg}$, v.o.) foi usada como controle positivo do teste.

\section{Avaliação da atividade antiulcerogênica}

\section{Lesão gástrica induzida por indometacina}

Ratos Wistar foram previamente tratados com extrato etanólico $(50,100$ e $200 \mathrm{mg} / \mathrm{kg})$, ranitidina (50 $\mathrm{mg} / \mathrm{kg})$ e salina $(10 \mathrm{~mL} / \mathrm{kg})$ por via oral. Indometacina $(30 \mathrm{mg} / \mathrm{kg}$ ) foi administrada subcutaneamente após 30 minutos de tratamento (Djahanguri, 1969). Após 4 horas da administração do agente ulcerogênico, os animais foram sacrificados, seus estômagos removidos e abertos ao longo da pequena curvatura. $O$ índice de lesão ulcerativa de cada animal foi calculado de acordo com a metodologia descrita por Gamberini et al. (1991): perda da morfologia normal (1 ponto), descoloração da mucosa (1 ponto), edema na mucosa ( 1 ponto), hemorragias ( 1 ponto), até 9 petéquias ( 2 pontos), mais de 10 petéquias ( 3 pontos), úlceras até $1 \mathrm{~mm}$ ( $\mathrm{n}^{\mathrm{o}}$ de úlceras $\mathrm{x} 2$ pontos), úlceras maior que $1 \mathrm{~mm}$ ( $\mathrm{n}^{\circ}$ de úlceras $\times 3$ pontos) e úlceras perfuradas ( $\mathrm{n}^{\mathrm{o}}$ de úlceras $\mathrm{x} 4$ pontos).

\section{Lesão gástrica induzida por etanol absoluto}

Os animais foram tratados com extrato etanólico $(50,100$ e $200 \mathrm{mg} / \mathrm{kg})$, ranitidina $(50 \mathrm{mg} / \mathrm{kg})$ e salina $(10 \mathrm{~mL} / \mathrm{kg})$ por via oral. Após 30 minutos de tratamento, cada animal recebeu oralmente $10 \mathrm{~mL} / \mathrm{kg}$ de etanol absoluto de acordo com a metodologia de Robert et al. (1979). Após 1 hora da administração do etanol, os animais foram sacrificados, seus estômagos removidos e abertos ao longo da pequena curvatura. $\mathrm{O}$ índice de lesão ulcerativa de cada animal foi determinado de acordo com a metodologia descrita por Gamberini et al. (1991).

\section{Volume gástrico e pH}

Após remoção do estômago, o suco gástrico foi coletado através de uma pequena incisão próximo ao piloro seguido da medição do volume. A determinação do $\mathrm{pH}$ do suco gástrico foi realizada usando uma pHmetro digital de bolso.

\section{Análise estatística}

Os resultados foram demonstrados através da média \pm desvio padrão. Análise de variância (ANOVA) seguida do teste de Student Newman-Keuls foi utilizada para medir o grau de significância $(\mathrm{p}<0,05)$ das médias dos resultados experimentais em relação ao grupo controle.

\section{RESULTADOS}

O extrato etanólico não foi tóxico aos animais tratados apresentando uma $\mathrm{DL}_{50}$ acima de $3 \mathrm{~g} / \mathrm{kg}$. No entanto, os resultados demonstraram que as doses de 50, 100 e $200 \mathrm{mg} / \mathrm{kg}$ do extrato etanólico de E. erythropappus reduziram as contorções abdominais em 43,07, 69,34 e $70,07 \%$, respectivamente (Tabela 1). A indometacina inibiu em 79,01\% as contorções, mostrando sua eficácia como analgésico e antiinflamatório.

A injeção intraplantar de formalina promoveu uma resposta característica bifásica (Tabela 1). A duração do tempo de lambida na primeira fase (0-5 min) foi de $85,10 \pm 9,15$ segundos e na segunda fase (15-30 $\min$ ) foi de $86,20 \pm 7,77$ segundos para o grupo controle. Após 60 minutos de tratamento, as doses de 50, 100 e $200 \mathrm{mg} / \mathrm{kg}$ inibiram a primeira fase em 11,52, 18,10 e $52,64 \%$ e a segunda fase em $8,35,13,46$ e $51,74 \%$, respectivamente. Como esperado, a morfina $(5 \mathrm{mg} / \mathrm{kg})$ foi ativa em ambas as fases.

O extrato etanólico de E. erythropappus aumentou o tempo de latência de camundongos expostos à placa quente (Tabela 2). No tempo 0 , não houve efeito significativo quando comparado ao grupo controle. Após 30, 60 e 90 minutos de tratamento, a dose de 200 $\mathrm{mg} / \mathrm{kg}$ aumentou o tempo de latência em 54,58, 80,77 e 77,92\%, respectivamente. A morfina mostrou-se um potente analgésico, aumentando o tempo de latência nos tempos avaliados. A naloxona, um antagonista opióide, reduziu o efeito da morfina, mas não alterou o efeito antinociceptivo do extrato testado.

$O$ efeito antiinflamatório do extrato de $E$. erythropappus avaliado pelo método do edema de pata induzido por carragenina é mostrado na Tabela 3 . A inibição do edema foi observada nas doses de 100 $\mathrm{mg} / \mathrm{kg}(23,81 \%)$ e $200 \mathrm{mg} / \mathrm{kg}(47,62 \%)$ em relação ao controle. A indometacina reduziu o edema de pata em $55,24 \%$.

Os resultados do teste de atividade antiulcerogênica mostrou que, após indução das lesões ulcerativas por indometacina, a dose de $100 \mathrm{mg} / \mathrm{kg}$ do extrato etanólico reduziu o índice de lesões ulcerativas em $16,11 \%(\mathrm{p}<0,05)$, enquanto $200 \mathrm{mg} / \mathrm{kg}$ produziram $27,71 \%(p<0,01)$ de inibição (Tabela 4). A dose de $200 \mathrm{mg} / \mathrm{kg}$ reduziu o volume gástrico e aumentou o $\mathrm{pH}$ de forma significativa. A dose de $200 \mathrm{mg} / \mathrm{kg}$ reduziu as lesões ulcerativas em 32,26\% (p<0,001) e volume gástrico em $27,07 \%$ após indução de úlceras por etanol (Tabela 5). $\mathrm{O} \mathrm{pH}$ do suco gástrico aumentou nas doses de $100(2,12 \pm 0,12)$ e $200 \mathrm{mg} / \mathrm{kg}(2,62 \pm 0,19)$ quando comparadas ao controle $(1,87 \pm 0,19)$. 
Tabela 1. Efeitos do extrato etanólico de E. erythropappus sobre as contorções abdominais induzidas por ácido acético e sobre o tempo de reação da lambida induzido, por formalina $(n=8)$.

\begin{tabular}{lcccc}
\hline Grupo & Doses $(\mathrm{mg} / \mathrm{kg})$ & Número de contorções & \multicolumn{2}{c}{ Tempo de reação (segundos) } \\
\cline { 3 - 5 } & & & $1^{\mathrm{a}}$ Fase & $2^{\mathrm{a}}$ Fase \\
\hline Controle & Salina & $54,80 \pm 6,05$ & $85,10 \pm 9,15$ & $86,20 \pm 7,77$ \\
& 50 & $31,20 \pm 5,45^{* * *}$ & $75,30 \pm 7,60^{*}$ & $79,00 \pm 5,91^{*}$ \\
Extrato & 100 & $16,80 \pm 3,39^{* * *}$ & $69,70 \pm 5,33^{* *}$ & $74,60 \pm 6,45^{* *}$ \\
& 200 & $16,40 \pm 3,37^{* * *}$ & $40,30 \pm 6,68^{* * *}$ & $41,60 \pm 6,29^{* * *}$ \\
Indometacina & 10 & $11,50 \pm 3,89^{* * *}$ & - & - \\
Morfina & 5 & - & $18,40 \pm 4,00^{* * *}$ & $5,20 \pm 1,39^{* * *}$ \\
\hline
\end{tabular}

${ }^{*} \mathrm{p}<0,05 ; * * \mathrm{p}<0,01 ; * * * \mathrm{p}<0,001$. Significativos após análise de variância (ANOVA) seguido do teste de Student Newman-Keuls quando comparados ao grupo controle (salina).

Tabela 2. Efeitos do extrato etanólico de E. erythropappus sobre o tempo de latência de camundongos expostos à placa quente (n $=8)$.

\begin{tabular}{lccccc}
\hline \multirow{2}{*}{ Grupo } & Doses & \multicolumn{4}{c}{ Tempo de Latência (s) } \\
\cline { 3 - 6 } & $(\mathrm{mg} / \mathrm{kg})$ & 0 & $30^{\prime}$ & $60^{\prime}$ & $90^{\prime}$ \\
\hline Controle & Salina & $6,50 \pm 1,60$ & $6,87 \pm 1,13$ & $6,50 \pm 1,95$ & $6,25 \pm 1,03$ \\
& 50 & $6,75 \pm 1,67$ & $6,75 \pm 1,28$ & $6,50 \pm 0,96$ & $6,37 \pm 0,92$ \\
Extrato & 100 & $6,50 \pm 1,60$ & $6,87 \pm 1,46$ & $6,62 \pm 0,92$ & $6,37 \pm 1,06$ \\
& 200 & $6,62 \pm 1,19$ & $10,62 \pm 1,68^{* * *}$ & $11,75 \pm 1,39^{* * *}$ & $11,12 \pm 0,99^{* * *}$ \\
Morfina & 1 & $6,75 \pm 1,49$ & $18,50 \pm 1,19^{* * *}$ & $21,36 \pm 1,77^{* * *}$ & $24,37 \pm 1,41^{* * *}$ \\
Naloxona+Morfina & $1+5$ & $6,62 \pm 2,19$ & $12,12 \pm 1,73^{* * *}$ & $10,25 \pm 1,03^{* * *}$ & $9,87 \pm 1,25^{* * *}$ \\
Naloxona+Extrato & $1+200$ & $6,25 \pm 2,25$ & $13,37 \pm 1,50^{* * *}$ & $12,12 \pm 0,99^{* * *}$ & $11,25 \pm 1,67^{* * *}$ \\
\hline
\end{tabular}

$* * * \mathrm{p}<0,001$. Significativos após análise de variância (ANOVA) seguido do teste de Student Newman-Keuls quando comparados ao grupo controle (salina).

Tabela 3. Efeitos do extrato etanólico de E. erythropappus sobre o edema de pata induzido por carragenina $(\mathrm{n}=6)$.

\begin{tabular}{lccc}
\hline Grupo & Doses $(\mathrm{mg} / \mathrm{kg})$ & Volume Deslocado $(\mathrm{mL})$ & Inibição $(\%)$ \\
\hline Controle & Salina & $1,05 \pm 0,19$ & - \\
& 50 & $1,05 \pm 0,17$ & - \\
Extrato & 100 & $0,80 \pm 0,09^{*}$ & 23,81 \\
& 200 & $0,55 \pm 0,10^{* * *}$ & 47,62 \\
Indometacina & 10 & $0,47 \pm 0,12^{* * *}$ & 55,24 \\
\hline
\end{tabular}

${ }^{*} \mathrm{p}<0,05 ; * * * \mathrm{p}<0,001$. Significativos após análise de variância (ANOVA) seguido do teste de Student Newman-Keuls quando comparados ao grupo controle (salina).

Tabela 4. Efeitos do extrato etanólico de E. erythropappus sobre as lesões gástricas induzidas por indometacina $(\mathrm{n}=6)$.

\begin{tabular}{lcccc}
\hline Grupo & Doses $(\mathrm{mg} / \mathrm{kg})$ & Índice ulcerativo & Volume gástrico $(\mathrm{mL})$ & $\mathrm{pH}$ \\
\hline Controle & Salina & $44,50 \pm 5,58$ & $1,27 \pm 0,19$ & $1,95 \pm 0,19$ \\
& 50 & $43,83 \pm 4,17$ & $1,22 \pm 0,15$ & $1,98 \pm 0,12$ \\
Extrato & 100 & $37,33 \pm 3,50^{*}$ & $1,12 \pm 0,23$ & $2,18 \pm 0,23$ \\
& 200 & $32,17 \pm 3,66^{* *}$ & $0,87 \pm 0,16^{* *}$ & $2,73 \pm 0,22^{* * *}$ \\
Ranitidina & 30 & $9,17 \pm 3,49^{* * *}$ & $0,55 \pm 0,10^{* * *}$ & $3,55 \pm 0,19^{* * *}$ \\
\hline
\end{tabular}

$* \mathrm{p}<0,05 ; * \mathrm{p}<0,01 ; * * \mathrm{p}<0,001$. Significativos após análise de variância (ANOVA) seguido do teste de Student Newman-Keuls quando comparados ao grupo controle (salina).

Tabela 5. Efeitos do extrato etanólico de E. erythropappus sobre as lesões gástricas induzidas por etanol $(\mathrm{n}=6)$.

\begin{tabular}{lcccc}
\hline Grupo & Doses $(\mathrm{mg} / \mathrm{kg})$ & Índice ulcerativo & Volume gástrico $(\mathrm{mL})$ & $\mathrm{pH}$ \\
\hline Controle & Saline & $46,83 \pm 4,07$ & $1,33 \pm 0,22$ & $1,87 \pm 0,19$ \\
& 50 & $46,50 \pm 4,89$ & $1,32 \pm 0,19$ & $1,93 \pm 0,14$ \\
Extrato & 100 & $44,67 \pm 4,13$ & $1,25 \pm 0,15$ & $2,12 \pm 0,12^{*}$ \\
& 200 & $31,50 \pm 4,32^{* * *}$ & $0,97 \pm 0,16^{* *}$ & $2,62 \pm 0,19^{* * *}$ \\
Ranitidina & 50 & $12,00 \pm 3,85^{* * *}$ & $0,63 \pm 0,16^{* * *}$ & $3,43 \pm 0,19^{* * *}$ \\
\hline
\end{tabular}

${ }^{*} \mathrm{p}<0,05 ;{ }^{* *} \mathrm{p}<0,01 ;{ }^{* * *} \mathrm{p}<0,001$. Significativos após análise de variância (ANOVA) seguido do teste de Student Newman-Keuls quando comparados ao grupo controle (salina). 


\section{DISCUSSÃO}

Baseado nos resultados observados neste estudo, o extrato etanólico de E. erytrhopappus possui propriedades antinociceptiva sobre o Sistema Nervoso Periférico e Central. Os resultados dos testes demonstram que o extrato reduziu as contorções abdominais, sugerindo a inibição da síntese de prostaglandinas pela via da ciclooxigenase (Duarte et al., 1992). Além disso, foi observado um efeito central e periférico através de uma resposta bifásica do tempo da lambida da pata induzida por formalina (Hunskaar \& Hole, 1987). A ação central foi confirmada no teste da placa quente $(200 \mathrm{mg}$ / $\mathrm{kg}$ ), mostrando que o efeito máximo é alcançado após 60 minutos da resposta. Estes resultados indicaram que a ação antinociceptiva do extrato não é exclusivamente dependente do sistema opióide, pois o tratamento com naloxona, antagonista opióide, não reverteu o efeito produzido. O teste do tempo da lambida da pata também sugeriu uma possível atividade antiinflamatória.

A atividade antiinflamatória do extrato etanólico de E. erythropappus sugerida no teste da formalina foi confirmada pelo modelo do edema da pata induzido por carragenina através da redução do volume deslocado (Tabela 4). Como agente inflamatório, a carragenina induz inflamação pela liberação de prostaglandinas, ocasionando a formação de um edema. Antiinflamatórios não-esteróides, como a indometacina, inibem a ciclooxigense, reduzindo a biossíntese de prostaglandina (Farsam et al., 2000). Provavelmente, o extrato testado possui ação semelhante a este antiinflamatório.

Os resultados indicam que o extrato etanólico de E. erythropappus previne lesões gástricas, reduz o suco gástrico e aumenta o pH gástrico após indução de úlceras por indometacina e por etanol. A ulceração gástrica induzida por indometacina é decorrente da inibição da síntese de prostaglandinas (Wallace, 2001). As lesões gástricas induzidas por etanol envolvem a depressão dos mecanismos de defesa gástrica, assim como a redução da produção do muco, do fluxo sangüíneo da mucosa gástrica, da secreção de bicarbonato, da glutationa endógena e das prostaglandinas (Kinoshita et al., 1995). Além disso, a ação do etanol aumenta a liberação de histamina, influxo de cálcio, geração de radicais livres e produção de leucotrienos (Glavin \& Szabo, 1992). É possível que constituintes do extrato testado estejam inibindo uma ou mais vias que promovem as lesões ulcerativas.

Em acordo com os resultados obtidos concluímos que o extrato etanólico de E. erythropappus demonstrou ter efeitos antinociceptivo, antiinflamatório e antiulcerogênico nos métodos empregados, sugerindo suas potencialidades para fins terapêuticos. Os resultados podem estar relacionados ao seu uso na medicina popular, entretanto, novos estudos necessitam ser realizados para garantir o uso seguro pela população.

\section{AGRADECIMENTOS}

Nossos agradecimentos ao CNPq e a UFJF pelas bolsas de iniciação científica.

\section{REFERÊNCIAS}

Braun NA, Meier M, Kohlenberg B, Hammaerschmidt F-J 2003. Two new bisabolene diols from the stem wood essential oil of Vanillosmopsis erythropappa SchultzBip. (Asteraceae). J Essent Oil Res 15: 139-142.

Corbrella A, Garilboldi P, Jomimi G 1974. Structure and absolute stereochemistry of vanillosmin, a guaianolide from Vanillosmopsis erythropappa. Phytochemistry 13: 459-465.

Dietrich L 1983. A new approach to practical acute toxicity testing. Arch Toxicol 54: 275-287.

Djahanguiri B 1969. The production of acute gastric ulceration by indomethacin in the rat. Scand J Gastroenterol 4: 265-267.

Duarte IDG, Ferreira-Alves DL, Nakamura-Craig M 1992. Possible participation of endogenous opioid peptides on the mechanism involved in analgesia by vouacapan. Life Sci 50: 891-897.

Farsam H, Amanlou M, Dehpour AR, Jahaniani F 2000. Antiinflammatory and analgesic activity of Biebersteinia multifida DC. root extract. J Ethnopharmacol 71 : 443-447.

Franzotti EM, Santos CVF, Rodrigues HMSL, Mourão RHV, Andrade MR, Antoniolli AR 2000. Anti-inflamatory, analgesic activity and acute toxicity of Sida cordifolia L. (Malva-branca). J Ethnopharmacol 72: 273-278.

Gamberini MT, Skorupa LA, Souccar C, Lapa AJ 1991. Inhibition of gastric secretion by a water extract from Baccharis triptera, Mart. Mem Inst Oswaldo Cruz 86: 137-139.

Glavin GB, Szabo S 1992. Experimental gastric mucosal injury: laboratory models reveal mechanisms of pathogenesis and new therapeutic strategies. FASEB $J$ 6: 825-831.

Hunskaar S, Hole K 1987. The formalin test in mice: dissociation between inflammatory and noninflammatory pain. Pain 30: 103-114.

Kinoshita M, Tsunehisa N, Tamaki H 1995. Effect of a combination of ecabet sodium and cimetidine on experimentally induced gastric-lesions and gastricmucosal resistence to ulcerogenic agents in rats. Biol Pharm Bull 18: 223-226.

Koster R, Anderson M, Beer EJ 1959. Acetic acid for analgesic screening. Fed Proc 18: 412.

Lima PDDB, Garcia M, Rabi JA 1985. Selective extraction of $\alpha$-methylene- $\gamma$-lactones, reinvestigation of Vanillosmopsis erythropappa. J Nat Prod 48: 986988.

Litchfield JT, Wilcoxon F 1949. A simplified method of evaluating dose-effect experiments. J Pharmacol Exp Ther 96: 99-113.

Pedralli G, Teixeira MCB, Nunes YR 1997. Estudos sinecológicos sobre a candeia (Vanillosmopsis erythropappa Schult. BIP) na estação ecológica de Tripui, Ouro Preto, MG. Rev Árvore 21: 301-306. 
Robert A, Nezamis JE, Lancaster C, Hauchar AJ 1979. Cytoprotection by prostaglandins in rats. Prevention of gastric necrosis produced by alcohol, $\mathrm{HCl}, \mathrm{NaOH}$, hypertonic $\mathrm{NaCl}$ and thermal injury. Gastroenterol 77: 433-443.

Silvério MS 2004. Estudo químico e farmacológico de Vanillosmopsis erythropappa Schultz Bip. (Asteraceae). Rio de Janeiro, 94 p. Dissertação de Mestrado - Programa de Pós-Graduação em Farmacologia e Terapêutica Experimental, Universidade Federal do Rio de Janeiro.

Sousa OV, Oliveira MS, Rabello SV, Cunha RO, Costa BLS, Leite MN 2003. Estudo farmacognóstico de galhos de Vanillosmopsis erythropappa Schult. Bip. Asteraceae. Rev Bras Farmacogn 13: 50-53.

Vichnewski W, Takahashi AM, Nasi AMT, Gonçalves DCRG, Dias DA, Lopes JNC, Goedken VL, Gutierrez AB, Herz W 1989. Sesquiterpene lactones and other constituents from Eremanthus seidelii, E. goyazensis and Vanillosmopsis erythropappa. Phytochemistry 28: 1441-1451.

Vichnewski W, Lopes JNC, Santos-Filho D, Herz W 1976. 15-Deoxygoyazensolide, a new heliangolide from Vanillosmopsis erythropappa. Phytochemistry 15: 1775-1776.

Wallace JL 2001. Mechanisms of protection and healing: current knowledge and future research. Am J Med 110: 19-22.

Winter CA, Risley EA, Nuss GW 1962. Carrageenininduced edema in hind paw of the rat as an assay for antiinflammatory drugs. Proc Soc Exp Biol Med 111: 544-547. 